\title{
IDENTIDADE, MEMÓRIA E PATRIMÔNIO
} A FESTA DE SANT'ANA DO RIO DO ENGENHO, ILHÉUS (BA)

\author{
Gisane Souza Santana (Uesc) \\ Maria de Lourdes Netto Simões (Uesc)
}

A festa de Sant'Ana do Rio do Engenho, entendida como patrimônio imaterial, contribui para afirmação das identidades culturais e revitalização das tradições. Para a discussão dos conceitos teóricos, toma-se a ideia das questões identitárias e do patrimônio cultural, observando-se a questão da memória. Com base nesses pressupostos teóricos, este estudo contribuirá para a valorização dos bens culturais, através da descrição e discussão dos elementos da memória - individual e coletiva.

MEMÓRIA; IDENTIDADE; PATRIMÔNIO; FESTA; RIO DO ENGENHO.

SANTANA, Gisane Souza; SIMÕES, Maria de Lourdes Netto. Identidade, memória e patrimônio: a festa de Sant'Ana do Rio do Engenho, Ilhéus (BA). Textos escolhidos de cultura e arte populares, Rio de Janeiro, v.12, n.1, p. 87-102, mai. 2015. 


\title{
IDENTITY, MEMORY AND HERITAGE \\ THE SANT'ANA FESTIVAL IN RIO DO ENGENHO, ILHÉUS (STATE OF BAHIA, BRAZIL)
}

\author{
Gisane Souza Santana (Uesc) \\ Maria de Lourdes Netto Simões (Uesc)
}

This is a study on the festival of Sant'Ana in Rio do Engenho, Ilheus, Bahia, Brazil. This festival, seen as intangible heritage, contributes to the affirmation of cultural identities and revitalization of traditions. For the discussion of theoretical concepts, we start with the idea of identity issues (Hall, 2005) and cultural heritage (London, 2004), observing memory issue (Pollak, 1989, Nora, 1992). Based on these theoretical assumptions, this study will contribute to the promotion of cultural assets through the description and discussion of the elements of memory - individual and collective.

MEMORY; IDENTITY; HERITAGE; FESTIVAL; RIO DO ENGENHO.

SANTANA, Gisane Souza; SIMÕES, Maria de Lourdes Netto. Identidade, memória e patrimônio: a festa de Sant'Ana do Rio do Engenho, Ilhéus (BA). Textos escolhidos de cultura e arte populares, Rio de Janeiro, v.12, n.1, p. 87-102, mai. 2015. 
Inserido no Território Litoral Sul, ${ }^{1}$ o município de Ilhéus se destaca como polo turístico, em virtude de seu rico patrimônio. De um lado, por sua riqueza cultural: literária, histórica, de manifestações através de festas, danças, gastronomia; de outro lado, pela beleza natural: praias, manguezais, cachoeiras, mata atlântica remanescente.

No século XX, o município era conhecido como o principal produtor da lavoura cacaueira; foi época de muitas riquezas e ostentação de poder dos coronéis do cacau, temática explorada pela literatura de Jorge Amado, Adonias Filho, Sosígenes Costa e outros. No entanto, nos anos 90 , além da podridão parda, a vassoura de bruxa assolou as roças de cacau, empobrecendo as terras dos chamados frutos de ouro.

Em função dessa crise econômica pela qual passou em decorrência da queda da monocultura cacaueira, o município de Ilhéus tem procurado investir em outras atividades, na tentativa de reerguer-se. Nesse contexto, o turismo cultural surge como uma das atividades que promoverá o desenvolvimento econômico da cidade. A valorização e preservação de saberes, modos de fazer, celebrações, música, literatura oral e conhecimentos tradicionais, por exemplo, surgem como meios que buscam promover o desenvolvimento cultural da comunidade.

Nessa perspectiva, está o Rio do Engenho - distrito rural de llhéus desde o tempo colonial, quando o atual município era Capitania de São Jorge dos Ilhéus. No distrito, as práticas simbólicas fazem parte de uma herança cultural de tradições e costumes que estão guardados na memória de alguns dos habitantes da região. Assim, por meio de festas, ofícios, rezas, folguedos, danças e artesanatos os moradores procuraram em seu percurso histórico articular saberes, corroborando a manutenção da vida social e cultural do distrito.

Este estudo analisa a festa de Sant'Ana - manifestação cultural característica da religiosidade popular que acontece todos os anos no mês de julho, no distrito rural do Rio do Engenho, na cidade de Ilhéus (BA), sustentando-se em três reflexões teóricas: na ideia das questões identitárias (HALL, 2005), incluindo consideração de que as identidades são dinâmicas; do patrimônio cultural (LONDRES, 2004), entendido no sentido largo, abrangendo bens materiais e imateriais; e, ainda, observando-se a questão da memória (POLLAK, 1992; NORA, 1993), como elemento fundamental da construção identitária. Com base no exposto, o texto foi estruturado em duas seções. A primeira, Lugar de memória, apresenta uma discussão sobre identidade, memória e patrimônio; a segunda, A festa de Sant'Ana, tece considerações sobre essa manifestação, identificando-a como patrimônio imaterial. Assim, este estudo intenta a valorização dos bens culturais, mediante a descrição e discussão dos elementos da memória. 


\section{LUGAR DE MEMÓRIA}

Entender a cidade como representação do social significa pensar nos matizes do comportamento humano, uma vez que ela se constitui em materialidades construtos patrimoniais -, e imaterialidades, decorrentes dos significados das práticas cotidianas conferidos pelos atores sociais ao longo do processo histórico. Sendo assim, o conceito de lugar pode ser entendido como resultado de práticas cotidianas e de processos de identificação que os atores sociais possuem em relação aos espaços de sociabilidade e vivência cultural. Dessa maneira, o lugar funciona como suporte da memória coletiva e da identidade social (HALBWACHS, 2006).

Desde o final do século XX, o tema patrimônio cultural assumiu papel importante nas questões referentes às identidades e à memória. Partindo de um discurso que restringia o conceito de patrimônio apenas aos bens físicos, esse conceito caminhou para uma concepção mais ampla, com base nos valores simbólicos que irão distinguir o bem cultural como singular, evocando não apenas sua história, mas também sua memória para seus descendentes.

A dilatação do conceito de patrimônio admite novas possibilidades de interpretação do patrimônio histórico e uma nova acepção que certifica a diversidade da existência humana e a inseparabilidade entre os grupos sociais e o meio ambiente. Desse modo, o ambiente e o patrimônio cultural revelam simbologias e representações que estão sendo consideradas nas estratégias de preservação de bens simbólicos.

Neste estudo, as práticas simbólicas, representadas por vivências cotidianas, hábitos, crenças e modos de fazer e viver em uma sociedade, são entendidas como patrimônio imaterial. Tais práticas são experiências que, segundo Certeau (1998), constituem-se como práticas ordinárias, ou seja, operações culturais que são movimentos do dia a dia. Dessa maneira, a memória das referências simbólicas "procura salvar o passado para servir o presente e o futuro" (LE GOFF, 1996, p. 423); e ainda avigora as tradições, repete códigos comportamentais, cria novos códigos e contribui para afirmação das identidades culturais.

Nesse entendimento, a memória é elemento fundamental da construção identitária. Para Pollak (1992), as identidades se constroem a partir de visões do passado, que funcionam como pontos de referência para determinados grupos e fornecem coerência, no tempo, a seus quadros de representação simbólica. Desse modo, a memória é um processo de ordenamento, de produção de sentido, que pressupõe enquadramentos, esquecimentos e silêncios. Acontecimentos e aspectos do passado são lembrados e sublinhados a partir de sua relevância para 
os indivíduos, que recordam por sua contribuição na construção da identidade e das relações pessoais. Assim sendo, a memória contribui para coesão social, definindo seu lugar, suas conexões, bem como seus conflitos.

No que diz respeito ao sentimento de pertença, esse não se pauta apenas na questão espacial; vincula-se também ao conceito de patrimônio cultural, o qual constitui, por meio da transmissão de saberes e fazeres da comunidade, elos de continuidade espaçotemporal, além de mecanismos de afirmação de identidade. O sentimento de pertencimento e permanência é o pressuposto básico para a construção da identidade.

Nessa perspectiva, entender a identidade como fixa e imutável corresponde apenas a uma estratégia para tentar formar nas consciências a sensação de homogeneidade que, na verdade, não corresponde mais ao conceito pós-moderno de identidade, devido aos processos de hibridização cultural. O sujeito pósmoderno, segundo Hall (2005, p. 37), é

conceptualizado como não tendo uma identidade fixa, essencial ou permanente (...) A identidade plenamente unificada, completa, segura e coerente é uma fantasia. Ao invés disso, à medida que os sistemas de significação e representação cultural se multiplicam, somos confrontados por uma multiplicidade desconcertante e cambiante de identidades possíveis com cada uma das quais poderíamos nos identificar - ao menos temporariamente.

Nesse entendimento, a identidade é considerada manifestação muito mais flexível; tem sido mais difícil a tarefa de se situar num ambiente mediado e formado por uma constante hibridação cultural, ou seja, em que "processos socioculturais nos quais estruturas ou práticas discretas, que existiam de forma separada, se combinam para gerar novas estruturas, objetos e práticas" (CANCLINI, 2003, p. 19). Os sujeitos passam a assumir diversas identidades, que não existem mais como algo unificado; todavia, respondem a momentos específicos e a contextos diversificados. Dessa maneira, mesmo com o hibridismo das culturas e formações múltiplas das identidades, surge a necessidade de se formularem estratégias que reúnam os indivíduos com algumas características comuns ao grupo e façam com que se sintam parte de um todo.

Para Hall (2005, p. 62), "uma forma de unificá-las tem sido a de representá-las como a expressão da cultura subjacente de 'um único povo'. A etnia é o termo que utilizamos para nos referirmos às características culturais - língua, religião, costume, tradições, sentimento de 'lugar' - que são partilhadas por um povo". Essas classificações das caracterizações do povo são fundamentais para gerar um agrupamento em torno dos mesmos aspectos culturais. 
Perceber a identidade como processo que emerge de atributos culturais é crucial, portanto, para a compreensão do papel que as representações têm na edificação dos sentidos que compõem as identidades. Assim, é possível dizer que só a partir da representação será possível conceituar a identidade explicando sua importância nas sociedades contemporâneas, nos domínios cultural e social. Nesse contexto, a cultura, enquanto expressão da produção de bens simbólicos que definem as identidades surge como uma síntese de representações capazes de produzir as identificações dos sujeitos com o meio no qual está inserido.

Nesse entendimento, memória e patrimônio estão inter-relacionados, já que ambos, quando ligados, fazem referência aos conhecimentos que conferem aos grupos sociais o sentido de pertença a uma determinada cultura e sociedade. A memória está pautada nas vivências e experiências coletivas, sendo ressignificadas no presente, como fio que conduz as tramas das relações que envolvem subjetividades dos diferentes grupos sociais; assim, "a memória é um elemento essencial do que se costuma chamar de identidade, individual ou coletiva, cuja busca é uma das atividades fundamentais dos indivíduos e das sociedades de hoje, na febre e na angústia" (LE GOFF, 1996, p. 472) .

Nesse sentido, é a memória que, ao definir o que é comum ao grupo e o que o diferencia, irá fundamentar e reforçar sentimentos de pertencimento. Dessa maneira, a memória, como lembrança, é viva, se realiza e consolida com o pertencimento (POLLAK, 1992). Assim, pode-se dizer que a memória é fruto do entrelaçamento das experiências de um momento vivido; é uma espécie de guardiã da integridade de cada grupo social, que assegura a sobrevivência de acontecimentos que marcaram um tempo e garante a partilha desses acontecimentos entre indivíduos de um grupo social. "A memória coletiva é apontada como um cimento indispensável à sobrevivência das sociedades, o elemento de coesão garantidor da permanência e da elaboração do futuro" (SANTOS, 1995, p. 239).

A memória, como "acervo de lembranças", não é um fruto qualquer que resulta de vivências, mas um processo que se faz no momento atual para atender às necessidades do presente. Deve-se afirmar com isso que o passado não é guardado pela simples evocação das lembranças, mas reconstruído numa dimensão atualizada. Daí poder-se dizer que a memória trabalha sobre o tempo - não um tempo qualquer, mas aquele experimentado pela cultura. Nas reminiscências, tece-se o passado no presente e entrelaçam-se novos conhecimentos. Como afirma Michael Pollak (1992, p. 209), a memória é "uma operação coletiva dos acontecimentos e das interpretações do passado que se quer salvaguardar".

Por sua vez, o patrimônio oferece aos membros de uma comunidade a possibilidade de eles perceberem sua origem, a de seus familiares e ancestrais, 
isto é, o patrimônio como representação da memória vincula os indivíduos a experiências de vivências individuais e coletivas, que caracterizam a trajetória de vida. O patrimônio cultural implica sentidos de pertencimento e permanência, considerando-se que a produção material e imaterial de uma comunidade tornase elo de identificação do grupo a um éthos cultural, vetor de transmissão e compartilhamento de experiências vividas.

A adesão afetiva ao grupo e a coletivização do patrimônio geram, em determinados espaços, lugares significantes, com os quais a comunidade se identifica; isso porque cristalizam fatos e/ou acontecimentos individuais e coletivos, que se vinculam às atividades cotidianas e, por conseguinte, fazem-se presentes na memória individual e coletiva dos grupos sociais. Sendo assim, o patrimônio cultural - material ou imaterial - que é construído a partir da memória coletiva inclui-se na categoria lugar de memória.

Conforme o historiador francês Pierre Nora (1993), os lugares de memória são identificados como espaços impregnados de conteúdo simbólico e de referências culturais. Para o historiador, a noção de lugar de memória deve corresponder aos três sentidos, material, simbólico e funcional, da palavra. O sentido material no entendimento do lugar em que a memória social se aporta; o simbólico, quando tem ou adquiriu a função de alicerçar memórias coletivas; e o funcional quando essa memória coletiva - vale dizer, essa identidade - se expressa e se revela. Como observa Nora (1993, p. 33),

os lugares de memória nascem e vivem do sentimento [de] que não há memória espontânea, [de] que é preciso criar arquivos, organizar celebrações, manter aniversários, pronunciar elogios fúnebres, notariar atas, porque estas operações não são naturais.

De tal modo, os lugares de memória se configuram fundamentalmente ao ser espaços em que a ritualização de uma memória-história pode suscitar a lembrança de conteúdos simbólicos e de monumentos reveladores dos processos históricos e culturais, dos conflitos sociais, dos interesses que, conscientemente ou não, os revestem de um papel icônico. Portanto, "só é lugar de memória se a imaginação o investe de uma aura simbólica (...) só entra na categoria se for objeto de um ritual" (NORA, 1993, p. 10).

Nessa perspectiva, o conceito de lugar de memória pode ser entendido como resultado das práticas sociais e do sentimento de pertença, revelando por sua vez a função identitária. Assim sendo, os lugares de memória constituem espaços de sociabilidade, compartilhamento de experiências, afirmação das identidades e reafirmação do sentido de territorialidade e de pertença à cultura local. Tais lugares funcionam como suporte da memória coletiva e da identidade social. 
Logo, pode-se dizer que o distrito rural do Rio do Engenho é um lugar de memória, de construção e atualização do passado. Tal distrito, localizado 20 quilômetros ao sul de llhéus (BA), às margens do Rio Santana, foi fundado a partir da divisão da Capitania de São Jorge dos Ilhéus em sesmarias. Construído por Mem de Sá, esse distrito de Ilhéus teve, no século XVI, um dos primeiros engenhos de açúcar do país, o Engenho de Santana, também conhecido como Engenho Real, que durante um longo período representou o centro econômico da capitania.

Segundo Marcis (2000), em 1570 havia oito engenhos em toda a Capitania de Ilhéus, restando, em 1724, apenas o Engenho de Santana; esse foi estrategicamente erigido às margens do Rio Santana para facilitar o escoamento da produção até o Porto de Ilhéus, de onde era transportada para Salvador. Conforme Schwartz (1988, p. 50), o local em que foi edificado o Engenho de Santana era atípico, porque

foi fundado distante do Recôncavo Baiano, área de grande concentração de escravos; foi coordenado por padres jesuítas durante muito tempo; a senzala não foi construída num local que possibilitasse ao administrador visualizá-la de sua residência; e as portas ficavam abertas, o que facilitava as fugas.

Devido à localização, era difícil contratar mão de obra para exercer as funções de mestre de açúcar, feitores e carpinteiros, cabendo aos negros assumi-las no engenho. Eles não eram remunerados, mas obtiveram, por reivindicações atributo que os diferenciava de escravos de outras partes do Brasil - diminuição do tempo de trabalho para cinco horas por dia.

Em 1789, entre o final do período colonial e os primeiros anos da independência, durante a administração de Manuel Silva Ferreira, o Engenho de Santana foi palco de uma histórica luta de escravos no Brasil. Segundo Schwartz (1988), os escravos se rebelaram, mataram o feitor e ocuparam o engenho, paralisando durante dois anos a produção de açúcar. O retorno à plantação só aconteceu após negociarem um Tratado de Paz com o proprietário do latifúndio. Durante esse período, os escravos tentavam administrar suas vidas, controlando as condições de escravização, por meio da manipulação do sistema. Eram feitas negociações e apenas quando não surtiam efeito, eles recorriam a fugas e ataques a seus senhores.

Os escravos do Engenho de Santana, tal como os índios, deixaram registrados para a história momentos importantes de luta e resistência. Especialmente no conflito e ocupação do Engenho de Santana, eles reivindicaram melhores condições de vida: direito de folgar, dançar e cantar; também formularam reivindicações trabalhistas, como: limitação da quantidade de canas por feixe, aumento 
do número de trabalhadores para o desenvolvimento de determinadas tarefas, a posse dos instrumentos de trabalho, maior tempo disponível para suas atividades pessoais, limitação da sua jornada de trabalho, etc. (MARCIS, 2000, p.70).

Esse acontecimento de luta e resistência dos escravos foi um marco histórico no Brasil devido às reivindicações por melhores condições de vida e afirmação de aspectos identitários.

No período de 1896 a 1960, a cultura do açúcar deixou de ser valorizada na região; houve transição da escravidão para o trabalho assalariado, e o cultivo da cana-de-açúcar foi substituído pelo do cacau. Naquela época, o município de Ilhéus ficou conhecido como o principal produtor da lavoura cacaueira; foi época de muitas riquezas e ostentação de poder. Nos anos 90, a vassoura de bruxa assolou as roças de cacau, empobrecendo a região.

Em função dessa crise econômica, o município de llhéus tem procurado investir em outras atividades, na tentativa de reerguer-se. A valorização e preservação de saberes, modos de fazer, celebrações, música e conhecimentos tradicionais, por exemplo, passam a ser considerados meios que contribuem para promover o desenvolvimento sociocultural da comunidade. Nesse contexto, surge, como uma das atividades que promoverá o desenvolvimento econômico da cidade, o turismo cultural - entendido como prática cujo objetivo consiste em valorizar e preservar os bens simbólicos tanto para a comunidade como para os visitantes.

\section{A FESTA DE SANT'ANA}

A Igreja de Sant'Ana integra o patrimônio histórico cultural do Rio do Engenho, e sua construção data provavelmente da primeira metade do século XVI. Os moradores do distrito rural e entorno - Cururutinga, Repartimento, Barro Branco, Tranquilidade, Santo Antônio - costumam frequentar a capela para participar de missas, festas religiosas, orações, cursos ou para contemplação de seus elementos singulares. A capela, patrimônio material, é considerada lugar sagrado, carregado de simbologias e representações acerca das tradições, o que a torna instrumento de formação social e identitária.

Outros indícios da antiguidade do distrito são as ruínas do engenho, o tacho de fazer o melaço da cana-de-açúcar, que foi encontrado enterrado, colocado à frente da capela, ruínas do canal que desviava a água do rio para mover a roda d'água e gerar a energia hidráulica. Devido à presença desses monumentos construídos antes de 1550 e tombados pelo Instituto de Patrimônio Histórico e Artístico Nacional - Iphan, esse distrito possui grande importância cultural. 
Além do patrimônio material, o distrito se destaca por sua riqueza imaterial: festa de Nossa Senhora Sant'Ana, gastronomia, artesanato, os saberes e fazeres cotidianos da comunidade e narrativas orais. Esses bens patrimoniais são materialidades e práticas culturais que se destacam nas manifestações populares por mediar diferentes e memoráveis fatos históricos e por representar heranças culturais, técnicas e estéticas de tempos passados.

Conforme Londres (2004, p. 22), o patrimônio imaterial é constituído por práticas, representações, expressões, saberes e fazeres - assim como instrumentos, objetos, artefatos e espaços culturais que lhe são associados - que comunidades, grupos e, quando for o caso, indivíduos reconhecem como parte de sua herança cultural. Esse patrimônio cultural imaterial, transmitido de geração em geração, é constantemente recriado por comunidades e grupos em resposta ao seu meio ambiente, sua interação com a natureza e suas condições históricas de existência, e lhes proporciona um sentido de identidade e continuidade, promovendo assim o respeito pela diversidade cultural e pela criatividade humana.

O conceito de patrimônio baseia-se nos valores simbólicos que irão distinguir o bem cultural como singular, evocando não apenas sua história, mas também sua memória e sua cultura para os contemporâneos e/ou seus descendentes. Tais valores são atribuídos ao patrimônio cultural através das práticas cotidianas, da identidade e da memória. Os bens provenientes do passado carregam traços culturais de seu tempo e são interpretados no presente, construindo espaços e ambientes diferentes. Esses espaços são ressignificados ou reconfigurados, sendo devolvidos à comunidade preservando seus aspectos históricos e culturais. As memórias coletivas se materializam através desses bens simbólicos que, ao ser exteriorizados, agem como um meio de socialização nas atividades coletivas desenvolvidas pelos grupos sociais.

Nesse sentido, as festas populares são um exemplo dessa reconfiguração em que o passado e o presente se entrelaçam nos rituais festivos. Dessa maneira, pensa-se na festa não apenas como rito do passado, mas também no entrelaçamento da história e cultura do tempo presente; e, ainda, no turismo, que atrai milhares de pessoas interessadas na riqueza religiosa, cultural ou histórica do lugar.

Segundo Ikeda e Pellegrini (2008, p. 208),

As festas representam momentos da maior importância social. São instantes especiais, cíclicos, da vida coletiva, em que as atividades comuns do dia a dia dão lugar às práticas diferenciadas que as transcendem, com múltiplas funções e significados sempre atuali- 
zados. As diversas espécies de práticas culturais populares podem ser a ocasião da afirmação ou da crítica de valores e normas sociais; o espaço da diversão coletiva; do repasto integrador; do exercício da religiosidade; da criação e expressão de realizações artísticas; assim como o momento da confirmação ou da conformação dos laços de identidade e solidariedade grupal.

Nesse entendimento, as festas exercem papel de destaque na relação entre o homem e o lugar, uma vez que essas manifestações culturais representam o modo como os grupos sociais concebem seu ambiente. As festas populares são consideradas momentos de grande importância para a sociabilidade e a construção das identidades individuais e coletivas.

Conforme Priore (2000), as festas tradicionais brasileiras não nasceram no Brasil, foram transplantadas pelos colonizadores portugueses e invasores do período colonial, que as consolidaram, dando-lhes certas especificidades. A festa religiosa em homenagem à padroeira Senhora Sant'Ana, do distrito do Rio do Engenho, é um exemplo: trazida pelos portugueses, foram-lhe acrescentados elementos das tradições africanas e indígenas. Tal festa estabelece novos sistemas de rituais e práticas que trilham pelo universo religioso e profano.

Nesse distrito rural, por meio da memória individual e coletiva, os moradores preservaram hábitos e crenças referentes ao modo de morar, cozinhar, lavrar a terra e festejar. As práticas de natureza rituais ou simbólicas, por repetição, inculcam certos valores e normas e dão continuidade ao passado. Desse modo, o espaço festivo reproduz os rituais das gerações anteriores, reforça as tradições, repete códigos comportamentais e também cria novos códigos.

A festa religiosa em homenagem à padroeira Senhora Sant'Ana, no dia 26 de julho, constitui manifestação da diversidade cultural da região. E sua atração reside em dois fatores: a fé dos devotos da santa e a capacidade do evento de reunir entretenimento e cultura popular. A fusão temporal de passado e presente se dá mediante elementos culturais, políticos, sociais e ideológicos dos grupos sociais.

A relação dos grupos sociais com o espaço festivo transforma a capela de Sant'Ana e seu entorno em espaço no qual se fazem presentes as memórias individual e coletiva, instituindo um sentimento de identidade, uma vez que "ela é também um fator extremamente importante do sentimento de continuidade e de coerência de uma pessoa ou de um grupo em sua reconstrução de si" (POLLAK, 1992, p. 204).

A devoção à santa se justifica pelas crenças que permaneceram no imaginário da comunidade. 
As construções de Igrejas geralmente são marcadas por lendas, que permanecem no imaginário das gerações atuais. A Igreja de Santana é um exemplo típico desse fenômeno. Conta a lenda que a Santa, insistentemente aparecia em uma pedra, dentro do rio Santana. Para os moradores, isso indicava que ela, a Santa, queria ficar próximo ao rio. Como os construtores da igreja haviam escolhido um local no alto do morro, as aparições continuavam. Os moradores contam que as aparições cessaram depois da construção da igreja próxima ao rio. Segundo eles, ainda é possível ver na pedra, as marcas dos pés da Santa (MARCIS, 2000, p. 71).

A celebração da festa de Sant'Ana preserva a cultura imaterial em seus aspectos mais importantes.

nove noite de festa...

A gente reza, canta, reza ladainha, agradece e pede... Vem gente de todo lugar, é uma festança muito bonita! Esse ano mesmo tenho uma promessa pra pagar...

(...) Ave Maria, num falto um dia, todo dia venho rezar a novena de Nossa Senhora. É maravilhoso demais... ela quis estar aqui nessa igreja. Ela aparecia aqui sempre. Ali [aponta a pedra], naquela pedra tem um sinal dos pé dela. Depois que os escravos construíram essa igreja, foi que sossegou, mas ela aparecia sempre.

Abaixo de Deus, só ela e Nossa Senhora... ela é mãe da mãe de Deus.

A gente prepara muita comida - doce, bolo, arroz-doce, canjica, licor. E aí, depois da novena alguma pessoa oferece arroz-doce, mugunzá, balas, pagando promessa, num sabe? Outros traz a oferenda e bota no rio.

No útlimo dia, todo mundo enfeita a igreja toda, enfeita o andor, reza o ofício, reza os bendito, reza a missa, faz a procissão, e depois é uma festança danada o dia todo.

(...)

Em março a gente celebra meu senhor São José, é o dia de plantar milho, feijão, depois vem São Jorge, Santa Rita, São João e São Pedro, Bom Jesus da Lapa, Nossa Senhora Aparecida, São Cosme e Damião, Santa Bárbara...

(Laura dos Santos, entrevista concedida no dia 18 de dezembro de 2013 [nas paredes da casa de dona Laura há vários quadros dos santos dos quais ela é devota. E ela explica que durante cada dia da novena uma família é responsável pela celebração]). 
DE acordo com dona Laura há um calendário devocional, fruto da vivência e religiosidade popular, que tem por fundamento a matriz católica e reúne homenagens a santos e também aos orixás. Isso evidencia que o significado dessas festas religiosas é amplo e abarca variadas experiências com o sagrado. Nesse contexto, por mais que se observe o catolicismo dominante, há uma grande diversidade nas práticas religiosas, que envolvem múltiplos pertencimentos religiosos.

A festa de Santana é um festejo popular de grande riqueza, com variedade de ofícios, modos de fazer e saberes a eles associados, como confecção de andor, preparação de alimentos, bordados das tolhas do altar, rezas, cânticos. Um aspecto que sobressai na análise das informações a seu respeito refere-se ao caráter sistêmico das relações entre famílias de ramais distintos. Nessa festa, os moradores reafirmam laços de solidariedade, praticam a sociabilidade, harmonizam-se, unem-se e, assim, nessa dinâmica, revelam novas facetas a suas identidades sociais. Tais eventos transformam-se em fatos sociais totais, nos quais se interpenetram distintos planos da organização social (Geertz, 1989) - econômicos, religiosos, estéticos e de parentesco.

As festividades, no Rio do Engenho, dedicadas à Senhora Sant'Ana realizam-se anualmente reunindo, além de moradores do distrito rural, as comunidades de Couto, Santo Antônio, Tranquilidade, Areia Branca, Cururutinga e outras. A festa ocorre no mês de julho e tem duração de nove dias, reunindo devotos da Senhora Sant'Ana. O início da festa é marcado por solenidade no dia 17 de julho com novena e missa, e o final, no dia 26, pela principal procissão em honra à santa de devoção. Após as missas, a festa continua nos bares e botecos, na festa de largo.

Entre os dias 17 e 26, a comunidade reza a novena e participa de missas realizadas sempre à noite. A programação dos festejos religiosos em homenagem à santa inclui novenas, alvorada, romarias e missa solene, momentos nos quais as pessoas reafirmam sua fé por meio das orações, ladainhas e cantos. O fervor religioso é manifestado na missa solene, na procissão, nas romarias, nos cânticos, nas ladainhas e nos pedidos encaminhados pelos fiéis. Devotos do distrito e do seu entorno comparecem para manifestar sua gratidão em relação à santa. Desse modo, a festa traduz a emoção e o sentimento do povo.

A festa é também o momento em que as tradições baianas são relembradas numa relação entre o sagrado e o profano presente ao longo de todas as atividades, desde a missa inaugural até o encerramento, costumeiramente com carnaval. Desse modo, moradores e turistas apreciam shows com bandas locais e servem-se da culinária típica do lugar, como moqueca de calambau, de robalo e de carapeba, e outros pratos à base de mariscos, como o catado de siri. Além dis- 
so, são vendidos e saboreados outros gêneros alimentícios resultantes da mistura étnica que aconteceu no lugar, como beijus, cocadas, doces em compota, geleias, acarajé e abará. Nesse período, a produção de doces e artesanatos se fortalece. Nesse entendimento, a festa apresenta-se como exemplo de fortalecimento da identidade local aliado à economia e ao turismo.

Assim, tudo se congraça pela festa, momento de celebração, do rompimento do ritmo do cotidiano, que permite ao homem experimentar, por meio de uma representação mítica, afetos, emoções e a manifestação divina. Tal processo envolve atribuição de significados às ações humanas. Nesse sentido, a festa de Sant'Ana revela a origem de respeito à fé e à fraternidade comunal, que alimenta as manifestações religiosas e perpetua as tradições do Rio do Engenho, constituindo um patrimônio cultural.

Nessas ocasiões, "as atividades humanas se voltam para a representação da existência de um grupo, revelando seus traços culturais" (MAZoco, 2007, p. 30).

Desse modo, a festa de Sant'Ana confere ao distrito rural do Rio do Engenho um espaço privilegiado, marcado pela peculiaridade histórica, memorialista e, sobretudo, pelo patrimônio cultural que envolve uma combinação de signos e tradições, consequência da mescla cultural dos grupos que a compõem, e que caracterizam o patrimônio. Surge, assim, a possibilidade de potencializar a cultura como recurso (YÚDICE, 2006) para o fortalecimento do tecido social.

Na comunidade do Rio do Engenho as práticas simbólicas perpetuam as experiências das gerações passadas, por meio das narrativas orais. Tais práticas possuem forte conteúdo simbólico, formando a base de um conhecimento tradicional que guia a escolha do tipo de solo, a época de plantio, a observação da maré e da lua para a pesca, o tempo para colheita, o trato e beneficiamento dos alimentos, a escolha do cipó para o artesanato, o preparo dos alimentos, os hábitos à mesa, o tempo para celebrações, os costumes e hábitos.

Assim, esses conhecimentos, construídos ao longo de diversas gerações, são importantes para o entendimento da história e identidade dessa comunidade. As narrativas contadas pelos depositários permitem-nos perceber não só a organização da vida cotidiana, a partir dos sujeitos que nela vivem, como também a valorização das estratégias de resistência das comunidades ao mundo globalizado.

\section{CONSIDERAÇÕES FINAIS}

A festa constitui um meio de transmissão de conhecimentos entre gerações. Representativa de contextos social, histórico e cultural, revela-se como área 
de estudo importante para compreensão das práticas cotidianas, reforçando a noção de patrimônio cultural como um bem coletivo. As manifestações populares transmitem o conhecimento deixado pelas etnias que contribuíram para a formação da identidade da região. As festas de religiosidade afro-brasileira traduzem a hibridização (CANCLINI, 2003) da cultura popular brasileira.

Assim sendo, a festa pode ser entendida como uma síntese de processos sociais e culturais, de um passado compartilhado pelos grupos sociais; pode ser considerada representação das práticas cotidianas, das tradições e vivências coletivas. Nessa perspectiva, no caso de Rio do Engenho, a prática simbólica da festa de Sant'Ana integra um conjunto de referências que permitem aos moradores do distrito torná-la significativa.

Nesse entendimento, a festa de Sant'Ana do Rio do Engenho é um lugar de memória, já que é resultado das práticas sociais, do sentimento de pertença e das referências culturais; e, ainda, suscita a lembrança de conteúdos simbólicos e de monumentos reveladores dos processos histórico e cultural. Essa manifestação constitui-se em espaços de sociabilidade, compartilhamento de experiências, afirmação das identidades e reafirmação do sentido de territorialidade. Por isso, essa festa funciona como suporte da memória coletiva e da identidade social.

\section{NOTA}

1 Terminologia proposta em 2008 no projeto do governo federal brasileiro Territórios de cidadania, para a confluência de ações de desenvolvimento sustentável em diversas áreas, incluindo a cultural (Sistema de Informações Territoriais. http://sit.mda.gov.br).

\section{REFERÊNCIAS BIBLIOGRÁFICAS}

CANCLINI, Néstor García. Culturas híbridas: estratégias para entrar e sair da modernidade. São Paulo: Edusp, 2003.

CERTEAU, M. A invenção do cotidiano: artes de fazer. Trad. Ephraim Ferreira Alves. Petrópolis: Vozes. 1998.

GEERTZ, Clifford. A interpretação das culturas. Rio de Janeiro: LTC, 1989.

HALBWACHS, M. A memória coletiva. São Paulo: Centauro, 2006.

HALL, Stuart. A identidade cultural na pós-modernidade. Trad. Guacira Lopes. Rio de Janeiro: DP \& A, 2005.

IKEDA, A. T.; PELLEGRINI FILHO, A. Celebrações populares: do sagrado ao profano. In: Terra paulista: histórias, artes, costumes, v. 3, Manifestações artísticas e celebrações populares no Estado de São Paulo. São Paulo: Imprensa Oficial/Cenpec, 2008. 
LE GOFF, Jacques. História e memória. 2 ed. Campinas: Editora da Unicamp, 1996.

LONDRES, Cecília. Patrimônio e performance: uma relação interessante. In. GARCIA, M. V. C; GUSMÃO, R.; TEIXEIRA, J. G. L. C. (Org.). Patrimônio imaterial, performance cultural e (re)tradicionalização. Brasília: ICS-UnB, 2004.

MARCIS, T. Viagem ao Engenho de Santana. Ilhéus: Editus, 2000.

MAZOCO, E. C. Festas e artesanato em terras do Espírito Santo. Rio de Janeiro: Iphan/CNFCP, 2007.

NORA, P. Entre memória e história - a problemática dos lugares. Projeto História: Revista do Programa de Estudos Pós-Graduados em História e do Departamento de História da PUC-SP. São Paulo, n. 10, dez. 1993.

POLLAK, M. Memória, esquecimento, silêncio. Estudos Históricos, Rio de Janeiro, v. 2, n. 3, 1992.

PRIORE, M. del. Festas e utopias no Brasil colonial. 2 ed. São Paulo: Brasiliense, 2000.

SANTOS, Idelette Muzart Fonseca. Escrituras da voz e memória do texto: abordagens atuais da literatura popular brasileira. In: BERND, Zilá; MIGOZZI, Jacques (Orgs.). Fronteiras do literário: literatura oral e popular Brasil/França. Porto Alegre: Editora da Universidade/UFRGS, 1995.

SCHWARTZ, S. B. Segredos internos: engenhos e escravos na sociedade colonial. São Paulo: Companhia da Letras, 1988.

YÚDICE, G. A conveniência da cultura. Usos da cultura na era global. Tradução Marie-Anne Kremer. Belo Horizonte: UFMG, 2006.

Gisane Souza Santana é mestranda no Programa de Pós-graduação em Letras, da Universidade Estadual de Santa Cruz. Bolsista Capes. Integrante do Grupo de Pesquisa Identidade Cultural e Expressões Regionais.

Maria de Lordes Netto Simões é doutora em estudos portugueses e pósdoutora em literatura comparada e turismo cultural, pela Universidade Nova de Lisboa. Pesquisadora sênior na Universidade Estadual de Santa Cruz. Integrante do Grupo de Pesquisa Identidade Cultural e Expressões Regionais.

Recebido em: 14/04/2014

Aceito em: 02/11/14 